Short Communication

\title{
Preparation and Properties of Nano-multilayer Films by Rotating Jet Electrodeposition
}

\author{
Lida Shen ${ }^{1, *}$, Kailin Zhao ${ }^{1}$, Mingbo Qiu, Xin Wang, Mingzhi Fan \\ College of Mechanical and Electrical Engineering, Nanjing University of Aeronautics and \\ Astronautics, No. 29 Yudao Street, Nanjing, Jiangsu 210016, PR China. \\ ${ }^{1}$ These authors contributed equally to this work. \\ *E-mail: 1dshen@nuaa.edu.cn
}

doi: $10.20964 / 2018.01 .47$

Received: 25 September 2017 / Accepted: 6 November 2017 / Published: 16 December 2017

\begin{abstract}
In the following paper, $\mathrm{Cu}-\mathrm{Ni}$ multilayer films were prepared by rotating jet electrodeposition (RJE). The $\mathrm{Cu}$ plating solution and the Ni plating solution were sprayed alternately during deposition to the rotating cathode surface through the corresponding nozzle. The cross-sectional morphology, microstructure, microhardness, and wear resistance of multilayer films were measured by scanning electron microscope, X-ray diffractometer, microhardness tester, and depth of field microscope, respectively. The results revealed that this novel method had no limit to the technological conditions and avoided the oxidation of the films which existed within the preparation of multilayer films by conventional electrodeposition. The sublayer boundaries of the obtained multilayer films were clear. A semi-coherent interface was formed between the sublayers. The resulting special structure reinforced the properties of the films. The microhardness of the multilayer films increased as the modulation period decreased. When the modulation period was reduced to less than $100 \mathrm{~nm}$, the hardness increased dramatically. In addition, the wear resistance of multilayer films was improved when the modulation period decreased.
\end{abstract}

Keywords: jet electrodeposition; multilayer films; modulation period; microhardness; wear resistance

\section{FULL TEXT}

(C) 2018 The Authors. Published by ESG (www.electrochemsci.org). This article is an open access article distributed under the terms and conditions of the Creative Commons Attribution license (http://creativecommons.org/licenses/by/4.0/). 